\title{
Combined Effects of Annealing and Cyclic Loading on Structural Rejuvenation and Mechanical Properties of CuZr Metallic Glass: A Molecular Dynamics Study
}

\author{
Agus Dwi Anggono", Mustafa Z. Mahmoud ${ }^{b, c}$, Wanich Suksatan ${ }^{d}$, Supat Chupradite, \\ Muneam Hussein Alif, Yasser Fakri Mustafa ${ }^{g}$, Hussein Mhaibes Tuama ${ }^{h}$,Aravindhan Surendari* (1) \\ ${ }^{a}$ Universitas Muhammadiyah, Faculty of Engineering, Surakarta, Jawa Tengah 57102, Indonesia. \\ ${ }^{b}$ Prince Sattam bin Abdulaziz University, College of Applied Medical Sciences, Department of Radiology \\ and Medical Imaging, Al-Kharj 11942, Saudi Arabia. \\ cUniversity of Canberra, Faculty of Health, Canberra, ACT, Australia. \\ ${ }^{d}$ Chulabhorn Royal Academy, Faculty of Nursing, HRH Princess Chulabhorn College of Medical \\ Science, Bangkok, Thailand. \\ ${ }^{e}$ Chiang Mai University, Faculty of Associated Medical Sciences, Department of Occupational Therapy, \\ Chiang Mai 50200, Thailand. \\ ${ }_{f}^{f}$ Al-Nisour University College, Baghdad, Iraq. \\ ${ }^{g}$ University of Mosul, Department of Pharmaceutical Chemistry, College of Pharmacy, Mosul-41001, Iraq. \\ ${ }^{h}$ Al-Ayen University, College of Physical Education and Sport Science, Thi-Qar, Iraq. \\ ${ }^{i}$ Saveetha Institute of Medical and Technical Sciences, Saveetha Dental College and Hospital, \\ Department of Pharmacology, Chennai, India.
}

Received: September 24, 2021; Revised: December 12, 2021; Accepted: December 18, 2021

Structural rejuvenation is one of the key topics in the field of metallic glasses (MGs). In this work, we evaluated the combined effects of annealing treatment and elastic cyclic loading to discover pathways for promoting structural rejuvenation and improving the mechanical properties in the MGs. Using molecular dynamics (MD) simulations, it was revealed that the sole cyclic loading led to the increase of rejuvenation degree; however, a saturated state was observed upon the $40^{\text {th }}$ cycle. On the other side, the sample exposed to the combined treatment exhibited a slight relaxation at the first step of cycling process and then a sharp rejuvenation degree was detected in the material. The thorough analyses indicated that the change in the fraction of coordination polyhedrons at the relaxation stage was the main reason for the extra rejuvenation in the sample exposed to the combined treatments. The results also suggest that the combination of rejuvenation treatments improves the magnitude of rejuvenation in the amorphous alloys. It should be noted that the increase of rejuvenation in the alloying systems accompanied with a reduction in the tensile strength and an enhancement in the homogenous plastic deformation.

Keywords: Metallic glass, molecular dynamics, rejuvenation, heterogeneity.

\section{Introduction}

Owing to the absence of conventional structural defects, bulk metallic glasses (BMGs) show outstanding properties such as excellent compressive strength, extensive elastic limit and high corrosion resistance ${ }^{1-4}$. However, their embrittlement at the room temperature restricts their potential applications in the industries ${ }^{5-7}$. To tackle this problem, it was suggested to excite the atomic structure of glassy alloys, namely rejuvenation, leading to the higher energy state with the better plasticity ${ }^{8,9}$. Several rejuvenating methods have been proposed by researchers to improve the energy state and the ductility of amorphous alloys ${ }^{10-14}$. Among them, external elastic loading without any macroscopic alteration of bulk sample is one of the favored techniques, tuning the mechanical properties and plasticity ${ }^{15-18}$. To provide some examples, Samavatian et al. ${ }^{19-21}$ indicated that the tensile

*e-mail: Surendararavindhan@ieee.org elastostatic loading leads to the significant disordering of short- and medium- atomic arrangements and induces the structural rejuvenation in the Zr-based BMGs. Their comprehensive study revealed that the interaction of stress domains under elastostatic loading is the main reason for the sharp variations of internal stresses at the atomic level, inducing the nanoscale heterogeneity in the amorphous alloy. Zhang et a ${ }^{22}$ reported that the elastostatic rejuvenation leads to the bimodal patterns of serration flows and shear bands. Using molecular dynamics (MD) simulation, it was unveiled that the prolonged elastostatic compression below the yield stress is manifested by the irreversible rearrangements of atoms and the increase in the typical size of atomic clusters with large non-affine displacements ${ }^{23,24}$. In another work, it was indicated that a mechanical relaxation-to-rejuvenation transition happens in the elastostatic compression ${ }^{25}$. It was suggested that the de-mixing tendency of the constituent 
atoms is dominated in the rejuvenation stage. Utiarahman et $\mathrm{al}^{26}$ determined that the pre-elastostatic loading before the cryogenic cycling treatment significantly improves the degree of rejuvenation increment in a Ce-based BMG. Using MD simulation, Chen et al. ${ }^{27}$ evaluated the structural features of MGs under the localized complex stress fields (LCSF). They found that the ultimate strength and elastic limits were increased in the LCSFed samples, which was due to the elimination of stress concentrations in the amorphous structure. Moreover, the investigations showed that a gradient rejuvenated amorphous structure increased the homogenous plasticity in the structure under the tensile loading ${ }^{28}$. This event was highlighted when the volume fraction and degree of structural disordering exceeded from a certain value.

The MD simulation of cyclic loading in a $\mathrm{CuZr}$ system indicated that the structural rejuvenation is associated with the nucleation and development of shear events in the bulk of $\mathrm{MG}^{29}$. Louzguine-Luzgin et al. ${ }^{30}$ demonstrated that the room-temperature cyclic loading up to $0.4 \%$ of elastic strain may induce the nanocrystallization in the amorphous material. Employing a kind of cyclic loading, i.e. the ultrasonic vibration, Lou et al. ${ }^{31}$ found that the high frequency strain energy is converted into internal energy owing to heterogeneous atomic packing configuration of MGs. The MD simulation also shows that the structural rejuvenation increases effectively with the rise in the cyclic loading number and ultimately reached a saturated regime ${ }^{32}$. Moreover, other works with different treating techniques reported the saturation of structural rejuvenation in the amorphous alloys ${ }^{33-36}$. Consequently, finding solutions for the enhancement of rejuvenation degree plays a crucial role in the improvement of structural features and plasticity. For this purpose, in this work, we employed the cyclic loading and annealing treatment simultaneously to promote the rejuvenation degree of an MG alloy and study the atomic structural evolution under the combined effects of treating methods. Using the MD simulation, the details of atomic rearrangement, potential energy landscape and structural heterogeneity are comprehensively discussed.

\section{Computational Method}

The Large-scale Atomic/Molecular Massively Parallel Simulator (LAMMPS) with the embedded atom method potential for $\mathrm{CuZr}$ alloys was applied to perform the MD simulations ${ }^{37}$. The favored alloying composition $\left(\mathrm{Cu}_{48} \mathrm{Zr}_{52}\right)$ for modelling the binary MG was obtained through randomly substitution of copper atoms in a $\mathrm{Zr}$-based crystalline atomic structure. The model respectively has sizes of $6 \times 6.5 \times 12 \mathrm{~nm}$ in the $\mathrm{x}, \mathrm{y}$ and $\mathrm{z}$ directions, while the system includes 17840 atoms. To create the model, the copper atoms were arranged in the FCC lattice cell and then the zirconium atoms (52 at. \%) were added into the alloying system by replacing the copper atoms. After the initial preparations, the atomic system was heated to $2100 \mathrm{~K}$ and kept in this temperature for $1 \mathrm{~ns}$. Hereafter, the glass formation was carried out with a quenching treatment to $20 \mathrm{~K}$ under the cooling rate of $1 \times 10^{12} \mathrm{~K} / \mathrm{s}$. The glassy system was then heated to the room temperature $(300 \mathrm{~K})$ for $2 \mathrm{~ns}$, leading to a relaxation and removal of cooling rate effects in the atomic configuration. It is worth-mentioning that a periodic boundary condition was applied in all the directions and the temperature and pressure were controlled by Nose-Hoover thermostat and barostat, respectively ${ }^{38}$. Using the isothermal-isobaric NPT ensemble, By comparing the atomic configurations before and after the induced stress, the regional von Mises strain of each constitute is computed ${ }^{32}$.

To evaluate the evolution of cyclic loading, MG models with cyclic numbers of zero to 50 were constructed. As observed in the Von Mises strain distributions (See Figure 1), the atomic rearrangement intensifies under the rise in the cycle number. However, one can see that local atomic movement lies in the range of elastic limit. Typically the elastic deformation in the MGs is correlated to the nanoscale non-affine shear events $^{29}$. Hence, the cyclic loading under the yield strength of MG leads to the local atomic reconfigurations with the alteration in the types and population of short- and mediumrange orders. However, the macroscopic dimensions of material remain unchanged ${ }^{39}$. In this work, the MG was exposed to the cyclic loading under a sinusoidal strain along the $\mathrm{z}$ direction ${ }^{32}$ :

$\varepsilon_{t}=\varepsilon_{0} \sin \left(\frac{2 \pi t}{t_{w}}\right)$

Where the values of $\mathrm{t}_{\mathrm{w}}$ and $\varepsilon_{0}$ are $0.2 \mathrm{~ns}$ and $3 \%$, respectively. It should be noted that the cyclic loading was conducted below the elastic limit and the lateral directions were adjusted to zero bar for observing any possible dimensional changes during the cyclic treatment. As illustrated in Figure 1, the cyclic loading was carried out at the temperature values of $300 \mathrm{~K}$ (room temperature) and $600 \mathrm{~K}$ to identify the role of temperature, i.e. annealing treatment, on the atomic structure of CuZr MG. For the high temperature treatment, the sample was heated to $600 \mathrm{k}$ and kept in this temperature for $1 \mathrm{~ns}$. Afterwards, the cycling loading was carried out and then the sample cooled down to the room temperature and a latter relaxation stage was considered to eliminate any effects of cooling rate. The heating and cooling rates were $10^{10} \mathrm{~K} / \mathrm{s}$. Moreover, the high temperature state $(600 \mathrm{~K})$ is below the glass transition temperature to avoid any possible crystallization. During the MD simulation of treatments, the pressure and temperature were controlled by the NPT ensemble. The uniaxial tensile loading of the $\mathrm{CuZr}$ glassy alloy simulated along the $\mathrm{z}$ direction with a constant strain

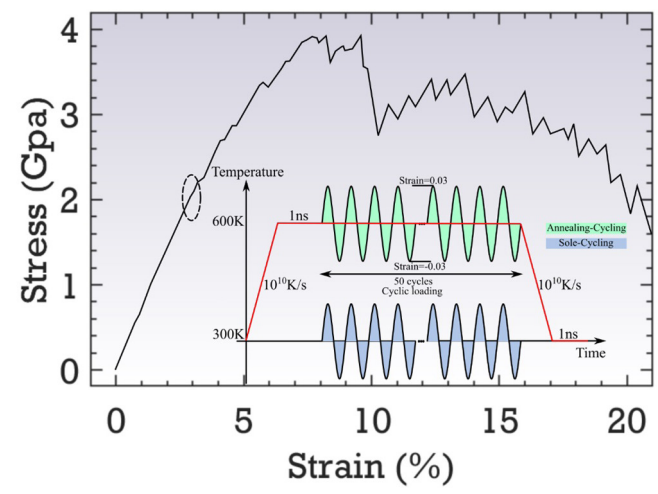

Figure 1. Schematic of stress-strain curves (inset shows the trend of cyclic loading process, conducted at the elastic limit). 
rate of $8 \times 10^{6} \mathrm{~s}^{-1}$ at $300 \mathrm{~K}$ to assess the effects of structural rejuvenation on the mechanical properties. In the simulation, the periodic boundary conditions in the different directions were considered, and the temperature and pressure were controlled by the NPT ensemble.

\section{Results and Discussion}

At the first step, it is critical to investigate the energy alterations and volume changes, which are indicators of rejuvenation in the amorphous alloys ${ }^{25,40}$. In general, the change in the potential energy of material indicates the stored energy in its atomic configuration. With the increase in potential energy, the nanoscale defects enhance in the system and the disordering event is intensified in the atomic arrangement of $\mathrm{MGs}^{41}$. As illustrated in Figure 2, the cyclic loading at $300 \mathrm{~K}$ leads to the positive change of potential energy $(\Delta \mathrm{E})$ for more than $260 \mathrm{eV}$, which means that the cyclic treatment induces structural disordering, i.e. rejuvenation, in the $\mathrm{CuZr}$ alloy. However, one can see that the $\Delta \mathrm{E}$ remained stable above the $\mathrm{N}=40$ and just fluctuated between $245-265 \mathrm{eV}$. Hence, it is concluded that a saturated energy state happens in the structure.
The degree of volume changes under the cyclic loading was also presented in Figure 2. The trends of bulk volume and potential energy are similar to each other, which indicates that the increase in energy state is accompanied with the generation of free volumes and loosely packed structures in the material ${ }^{42,43}$. Figure 2 also indicates the effects of simultaneous cyclic and annealing $(600 \mathrm{~K})$ treatments on the structural rejuvenation of $\mathrm{CuZr}$ glassy alloy. Under the 10 cycling number, some volume contraction and $\Delta \mathrm{E}$ decrement $(-70 \mathrm{eV})$ were observed, showing the dominant role of high temperature process. On the other side, a sharp increment is detected in both of volume and $\Delta \mathrm{E}$ up to the 45 cycling number and then a saturation happens in the structure. The results also demonstrated that the degree of $\Delta \mathrm{E}$ increment in the annealing/cyclic treatment is considerably higher than the MG alloy induced by the sole cyclic loading. This event confirmed that the high temperature treatment facilitated the nanoscale structural rearrangement under the cyclic loading.

The induced strain distribution of treated samples gives important information regarding the structural heterogeneity in the atomic configurations. Figure 3 illustrates the snapshots of Von-Mises after the certain number of cyclic loadings.

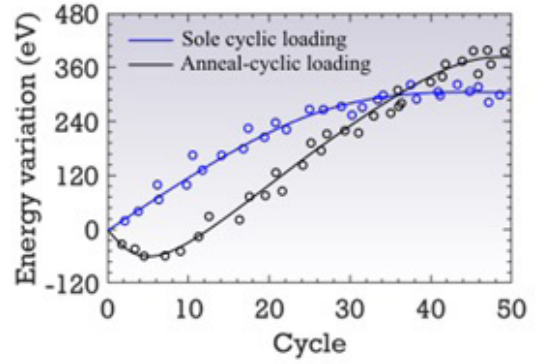

(a)

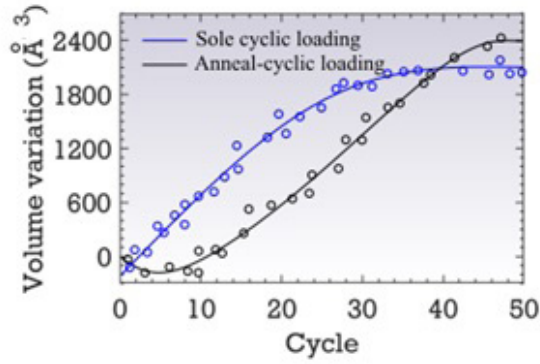

(b)

Figure 2. a) Potential energy variations and b) Volume variations as a function cycle numbers for the samples.
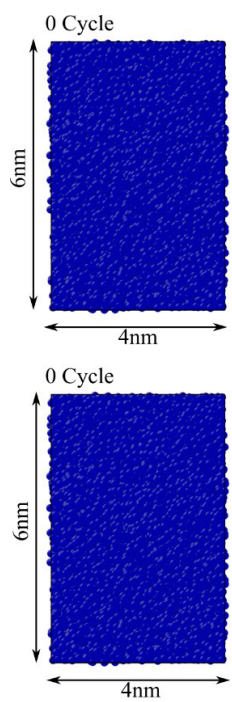
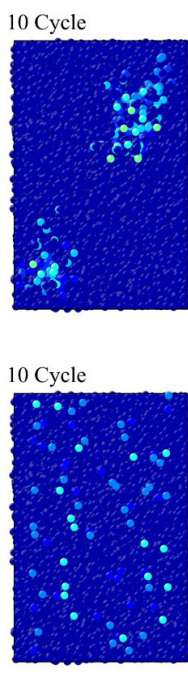
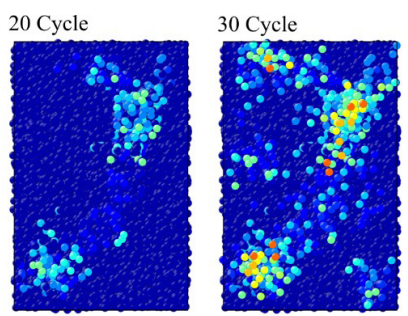

(a)
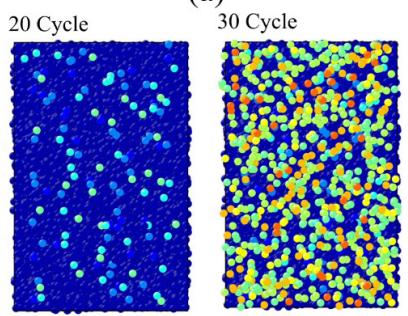
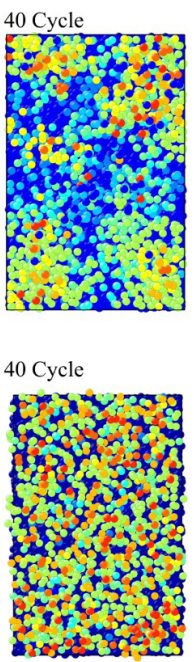

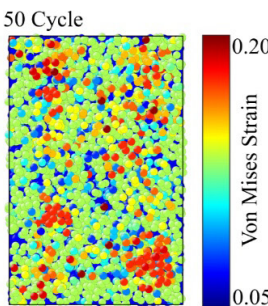

(b)

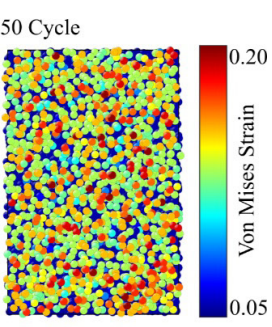

Figure 3. The Von Mises strain distribution of sample exposed to a) the sole cyclic loading and b) the annealing-cycling treatment. 
As observed, the cyclic loading leads to the introduction of strain into the system. However, one can see that the strain distribution changes when the annealing process comes into play. Under the combined treatment, no significant induced strain was detected at the first number of cycles, which was consistent with the negative variations of potential energy at the first stage. Thereafter, the induced increased in the system with rise in number of cycles. With the detailed observation of snapshots, it was indicated that there existed no accumulated strain regions in the atomic configuration of sample treated by annealing-cycling process. On the other side, some accumulated strains were detected in the sample treated by the sole cycling. In several works, it was unveiled that the increase in the intensification of strained regions in the atomic configuration goes along with the creation of potential sites for the initiation of nanoscale shear events ${ }^{44,45}$. In the other words, the structural heterogeneity was intensified in the sample treated by the annealing-cycling process, which may lead to the improvement of homogeneous plasticity under an external loading. In the following, the mechanical response and the plasticity behavior of samples under the tensile loading will be discussed.

To better understand the atomic reconfiguration under the cyclic loading, the partial pair distribution function (PDF) analysis was conducted. As presented in Figure 4, the PDF analysis provides information regarding the atomic density distribution as a function of atomic distances. The results showed that the sole cyclic loading leads to the slight shift of $\mathrm{Zr}-\mathrm{Zr}$ first peak to the lower values, while there is no significant change in the peak height. On the other side, the height of $\mathrm{Cu}-\mathrm{Cu}$ and $\mathrm{Cu}-\mathrm{Zr}$ first peaks show the increasing and decreasing trends under the sole cyclic loading, respectively. Hence, it is concluded that the number of $\mathrm{Cu}-\mathrm{Cu}$ pairs rises under the treatment, while the $\mathrm{Cu}-\mathrm{Zr}$ pairs tend to be annihilated. Moreover, one can see that the average interatomic distance of $\mathrm{Zr}-\mathrm{Zr}$ pairs gets constricted; however, their population in the atomic structure remains stable. On the other side, the combination of annealing and cyclic loading treatments leads to the different atomic rearrangement in the amorphous structure. As observed in Figure 4, there is no considerable shift in the $\mathrm{Zr}-\mathrm{Zr}$ peak; however, the peak intensity shows a slight increment. Moreover, the degree of $\mathrm{Cu}-\mathrm{Zr}$ annihilation is significantly higher than the sample treated under the sole cyclic loading. One can also see that the population of $\mathrm{Cu}-\mathrm{Cu}$ exhibited a slight decrement under the combined treatment. This result clearly indicated that the mechanism of rejuvenation in the samples is almost different, so that the sole cyclic loading tends to replace the $\mathrm{Cu}-\mathrm{Zr}$ pairs with $\mathrm{Cu}-\mathrm{Cu}$ ones in the first nearest-neighbor shell. On the other side, the sample under the combined treatment induces more $\mathrm{Zr}-\mathrm{Zr}$ pairs with longer bonding length through the sharp annihilation of $\mathrm{Cu}-\mathrm{Zr}$ pairs with shorter bonding length. Accordingly, it is suggested that the high temperature treatment significantly alters the type of atomic reconfiguration during the cyclic loading.

Figure 5a illustrates the stress-strain curves of rejuvenated samples under the tensile loading process. As clear in the figure, the tensile plasticity under the evolution of cyclic number is different in the samples, suggesting that the cycle number along with the applied temperature (annealing treatment) play a significant role in the deformation behavior of amorphous alloys. At the low number of cycles, the samples experienced a stress peak accompanied with a sharp decrement, which is a sign of strain localization under the tensile loading (See Figure 5b). This prompt strain localization is the main reason for the lower plasticity of untreated and low-cycled samples in comparison with the samples rejuvenated with the high number of cycles. Hence, the results showed that the increase in the number of cyclic numbers improves the plasticity and postpones the nanoscale shear localization in the amorphous structure. However, one should notice that the aspect ratio and the sample size in the MD simulation act as the crucial roles in the plasticity behavior of MGs. As depicted by Sopu et $\mathrm{al}^{46}$, the decrease of specimen size to the nanoscale regime, the strain softening is extended in the structure and the failure is deferred in the system. Moreover, it was found that the low aspect ratio inhibits the catastrophic failure under the tension mode, especially in the rejuvenated structures with high potential sites for the formation of nanoscale shear events ${ }^{46-48}$. Hence, it is concluded that the significant homogenous plastic deformation in the high-cycled samples may be related to the features of MD simulation.

Figure $5 \mathrm{~b}$ demonstrated the strain snapshots of selected regions in the stress-strain curves of samples. As can be seen, the cyclic loading significantly affects the strain distribution in the loaded samples. To provide some examples, the strain snapshots are presented for the samples exposed to the 10,20 and 30 cycles at the same stress values. According to the marked points in the stress-strain curves, the total induced strain in these samples are $\sim 11 \%, 14 \%$ and $18 \%$, respectively. However, the snapshots show that the strain distribution is different. In the sample loaded with 10 cycles, a shear localization along with a necking event occurred in the

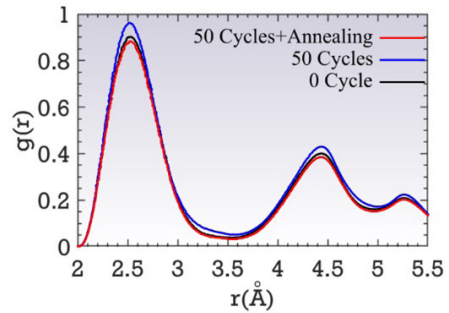

(a)

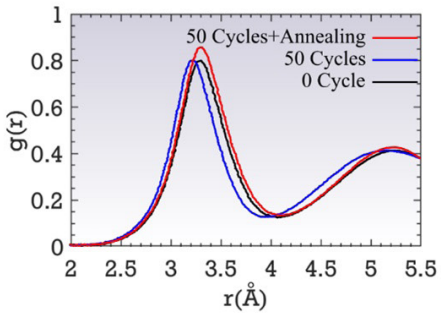

(b)

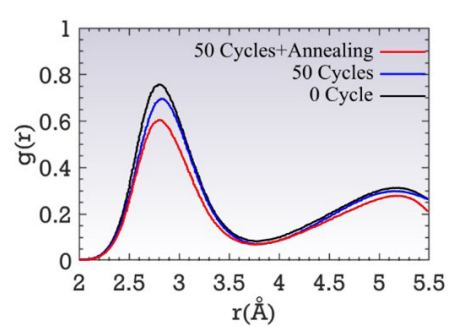

(c)

Figure 4. Partial pair distribution function for a) $\mathrm{Cu}-\mathrm{Cu}$, b) $\mathrm{Zr}-\mathrm{Zr}$, c) $\mathrm{Cu}-\mathrm{Zr}$. 


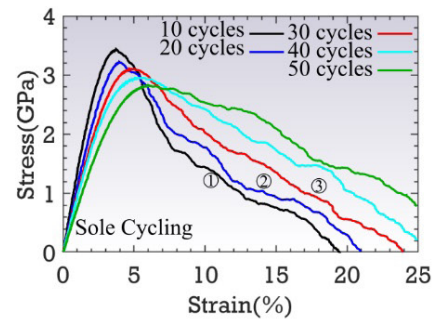

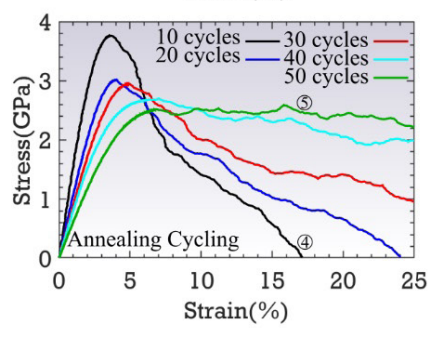

(a)

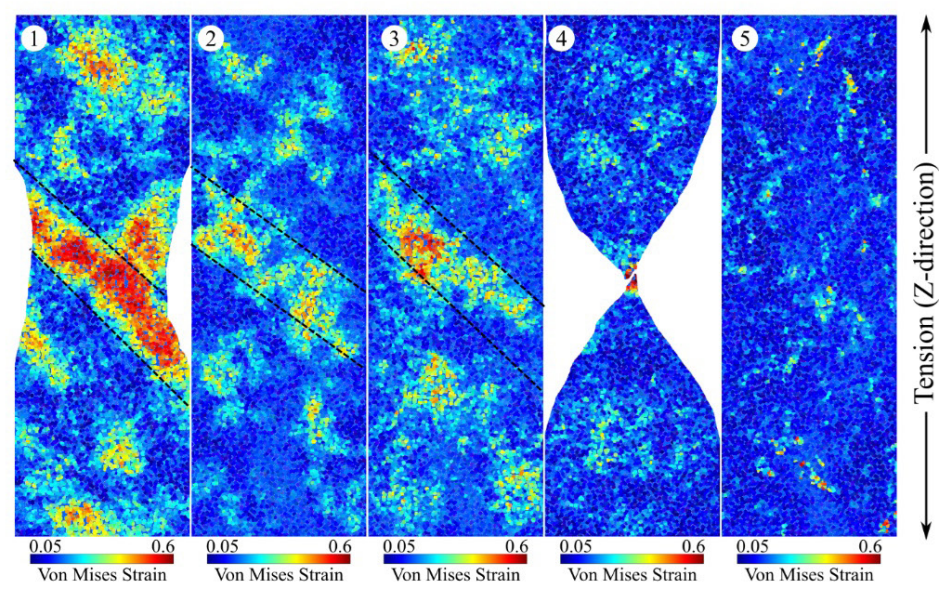

(b)

Figure 5. a) Stress-strain curves of samples under different cycling numbers, b) Von-Mises strain snapshots of selected regions marked in the stress-strain curves.

system, which is manifested in the sharp stress decrement in the stress-strain curve. On the other side, the strain distribution is less localized in the samples loaded by 20 and 30 cycles, suggesting the evolution of structural rejuvenation under the sole cyclic loading. The stress-strain curves also showed that the combination of annealing treatment and cyclic loading significantly improves the plasticity in the material, so that for the samples exposed to the 40 and 50 loading cycles, there is no sign of stress drop in the curves. This means that the plasticity mechanism in the samples can transform from a localized shear event to a homogenous plastic deformation. The snapshots of Von Mises strain also confirmed that the induced strain was homogenously distributed in the structure, inhibiting any immediate localized event during the tensile deformation. This phenomenon is due to the increase of structural heterogeneity under the rejuvenation process. In general, the structural rejuvenation induces more defects such as free volumes in the structure leading to a pronounced nanoscale heterogeneity with numerous potential sites for the shear events ${ }^{21,49,50}$. Consequently, the catastrophic failure by the localized deformation is replaced with the stable plastic flow in the rejuvenated sample.

To better understand the rejuvenation mechanism, it is necessary to interpret the energy state based on the potential energy landscape (PEL) $)^{41}$. Figure 6 illustrates the evolution of energy state under the sole cyclic loading and its combination with the annealing process. As can be seen, it is possible to describe the evolution of atomic rearrangement based on the local barrier energies. In general, the local atomic movement under an external excitation comprises two main energy stages, called the activation step $\left(\mathrm{E}_{\text {act }}\right)$ and relaxation step $\left(\mathrm{E}_{\mathrm{rel}}\right)$. With this definition, when the total energy of activation becomes bigger than the relaxation energy, the structural rejuvenation happens in the material ${ }^{36}$. As observed, the sole cyclic loading increased the total energy of alloying system from zero to 40 cycles and then a saturated situation

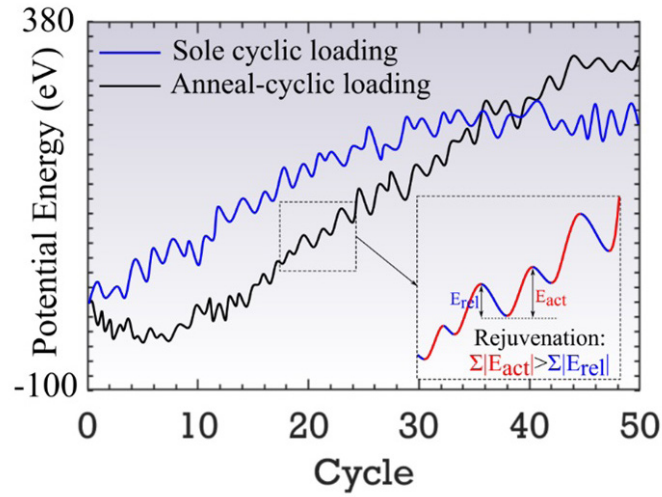

Figure 6. Schematic of potential energy landscape as a function of cycle numbers.

occurs, which means that the fluctuation of activation and relaxation stages remained stable after a certain number of cycle numbers. On the other side, in the sample treated by the annealing and cycling processes, a relaxation trend in the energy state was detected at the first cycling numbers and then the sharp activation events come into play from 10 to 40-45 cycle numbers. Agreeing with Figure 2, one can conclude that the annealing event provides conditions for facilitating the atomic rearrangement in the structure. Under the first relaxation event at low cycling numbers, the potential sites were produced to induce the $\mathrm{Zr}-\mathrm{Zr}$ pairs under the rejuvenation and significantly annihilate the $\mathrm{Cu}-\mathrm{Zr}$ pairs, as shown in Figure 4. Consequently, it is suggested that the creation of more $\mathrm{Zr}-\mathrm{Zr}$ atomic pairs under the combined treatment is the main reason for the sharp activation events in the rejuvenation of $\mathrm{CuZr}$ alloy.

For detailed characterization of atomic structure under the rejuvenation process, the coordination polyhedron study 


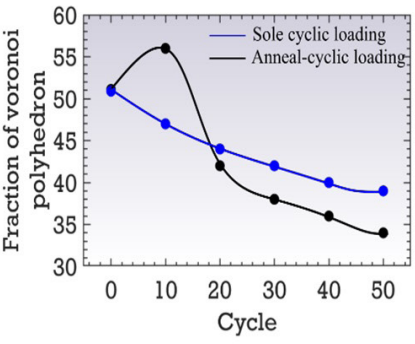

(a)

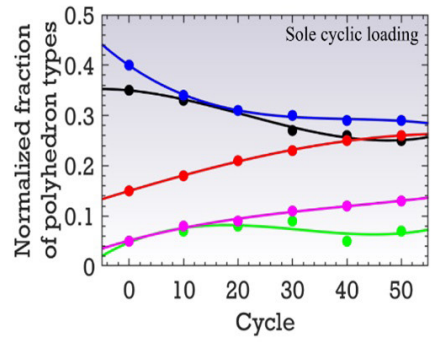

(b)

b)

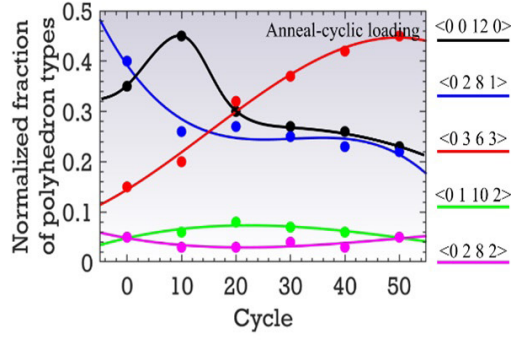

Figure 7. a) Polyhedron fractions in the samples as a function of cycle number, b) Normalized fractions of polyhedron types under evolution of rejuvenation process.

was conducted in accordance with the Voronoi tessellation. Totally, the Voronoi index is indicative of characteristics in a coordinated component, in which the number of n-edged faces of a Voronoi polyhedron, $<\mathrm{i}_{3}, \mathrm{i}_{4}, \mathrm{i}_{5}, \mathrm{i}_{6}>$, is introduced ${ }^{29}$. As given in Figure $7 \mathrm{a}$, the fraction of Voronoi polyhedron strongly depends on the evolution of rejuvenation/relaxation in the amorphous structure. The cu-centered clusters are favored in the $\mathrm{CuZr} \mathrm{MGs}{ }^{51}$, which means that the sum of coordination polyhedron comprises the backbone and main ordered structure of amorphous alloy. According to the results, the fraction of ordered structure gradually decreases in the sample exposed to the sole cyclic process and then a steady state upon the $40^{\text {th }}$ cycle number. On the other side, the sample exposed to the combined treatments shows a slight increment at the first stage of cyclic loading and then experiences a moderate decline of ordered structure, which is correlated to the structural rejuvenation. Figure $7 \mathrm{~b}$ reveals the normalized fraction of main coordination polyhedrons versus the cycle numbers for both samples.

As plotted in Figure 7b, the backbone of samples is dominated by the polyhedrons with indices of $\langle 0,2,8,1>$ and $\langle 0,0,12,0\rangle$. However, the fraction of polyhedrons is significantly affected under the evolution of treatment. As reported in Figure 2a, the potential energy decreases at the first stage (5-10 cycles) of annealing-cycling treatment in the sample, which shows a slight relaxation in the system. The Voronoi analysis indicated that the relaxation stage goes along with the sharp rise of polyhedron $<0,0,12,0\rangle$ in the structure, leading to the decrease of potential energy of amorphous structure. After this stage, the rejuvenation proceeds with the sharp rise of $\langle 0,3,6,3\rangle$ and the moderate decrement of $\langle 0,2,8,1\rangle$ and $\langle 0,0,12,0\rangle$ in the material. This event is far different from what happened in the sample exposed to the sole cycling process, in which a gradual increment in fractions of $<0282>$ and $<0,3,6,3>$ occurs under the rejuvenation. Consequently, it is suggested that the primary increase of $\langle 0,0,12,0\rangle$ icosahedral coordination structure in the system would be the main reason for the sharp rejuvenation of $\mathrm{CuZr}$ MGs under the combined effects of annealing and cycling processes.

\section{Conclusions}

This work aims to show the role of combined treatments on the magnitude of rejuvenation in the MGs. For this purpose, MD simulation was used to model the $\mathrm{CuZr} \mathrm{MG}$ under the sole and simultaneous application of annealing and cyclic loading. The results indicated the evolution of rejuvenation in the amorphous structure strongly depends on the type of treatment. Under the sole cyclic treatment, the rejuvenation degree gradually increases and reaches a saturated state after the $40^{\text {th }}$ cycle. On the other side, for the sample exposed to the combined treatment, a relaxation event was observed at the first steps and then a sharp increment of rejuvenation occurs with the advance of cycling loading. The results demonstrated that the alterations in the population of polyhedrons at the relaxation stage is the main reason for the change in the rejuvenation degree in the $\mathrm{CuZr}$ MG.

\section{References}

1. Deng L, Gebert A, Zhang L, Chen HY, Gu DD, Kühn U, et al. Mechanical performance and corrosion behaviour of $\mathrm{Zr}$ based bulk metallic glass produced by selective laser melting. Mater Des. 2020;189:108532. http://dx.doi.org/10.1016/j. matdes.2020.108532.

2. Mahmoud ZH, Barazandeh H, Mostafavi SM, Ershov K, Goncharov A, Kuznetsov AS, et al. Identification of rejuvenation and relaxation regions in a $\mathrm{Zr}$-based metallic glass induced by laser shock peening. J Mater Res Technol. 2021;11:2015-20. http://dx.doi.org/10.1016/j.jmrt.2021.02.025.

3. Obeydavi A, Shafyei A, Rezaeian A, Kameli P, Lee J-W. Microstructure, mechanical properties and corrosion performance of Fe44Cr15Mo14Co7C10B5Si5 thin film metallic glass deposited by DC magnetron sputtering. J Non-Cryst Solids. 2020;527:119718. http://dx.doi.org/10.1016/j.jnoncrysol.2019.119718.

4. Di S, Wang Q, Zhou J, Shen Y, Li J, Zhu M, et al. Enhancement of plasticity for FeCoBSiNb bulk metallic glass with superhigh strength through cryogenic thermal cycling. Scr Mater. 2020;187:138. http://dx.doi.org/10.1016/j.scriptamat.2020.05.059.

5. Qu R, Maaß R, Liu Z, Tönnies D, Tian L, Ritchie RO, Zhang $\mathrm{Z}$, Volkert CA. Flaw-insensitive fracture of a micrometer-sized brittle metallic glass. Acta Mater. 2018;2018:117219.

6. Zhang J, Wang X, Li M. From brittle to ductile transition: the influence of oxygen on mechanical properties of metallic glasses. J Alloys Compd. 2021;876:160023. http://dx.doi.org/10.1016/j. jallcom.2021.160023.

7. Langer JS. Brittle-ductile transitions in a metallic glass. Phys Rev E. 2020;101:63004. http://dx.doi.org/10.1103/ PhysRevE.101.063004.

8. Das A, Dufresne EM, Maaß R. Structural dynamics and rejuvenation during cryogenic cycling in a $\mathrm{Zr}$-based metallic glass. Acta Mater. 2020;196:723-32. http://dx.doi.org/10.1016/j. actamat.2020.06.063. 
9. Ryu W, Yamada R, Saida J. Tailored hardening of ZrCuAl bulk metallic glass induced by 2D gradient rejuvenation. NPG Asia Mater. 2020;12:52. http://dx.doi.org/10.1038/s41427-020-02338.

10. Meylan CM, Orava J, Greer AL. Rejuvenation through plastic deformation of a La-based metallic glass measured by fastscanning calorimetry. J. Non-Crystalline Solids X. 2020;8:100051. http://dx.doi.org/10.1016/j.nocx.2020.100051.

11. Zhou H, Hubek R, Peterlechner M, Wilde G. Two-stage rejuvenation and the correlation between rejuvenation behavior and the boson heat capacity peak of a bulk metallic glass. Acta Mater. 2019;179:308-16. http://dx.doi.org/10.1016/j. actamat.2019.08.040.

12. Wakeda M, Saida J. Heterogeneous structural changes correlated to local atomic order in thermal rejuvenation process of $\mathrm{Cu}-\mathrm{Zr}$ metallic glass. Sci Technol Adv Mater. 2019;20:632-42. http:// dx.doi.org/10.1080/14686996.2019.1624140.

13. Ebner C, Pauly S, Eckert J, Rentenberger C. Effect of mechanically induced structural rejuvenation on the deformation behaviour of CuZr based bulk metallic glass. Mater Sci Eng A. 2020;773:138848. http://dx.doi.org/10.1016/j.msea.2019.138848.

14. Chen Q, Zhang M, Gu J, Cao Q, Zhang C, Han X, et al. Expanding the homogeneous regime of deformation in bulk metallic glass by electromigration-induced rejuvenation. Commun Mater. 2020;1:44. http://dx.doi.org/10.1038/s43246-020-0046-x.

15. Greer AL, Sun YH. Stored energy in metallic glasses due to strains within the elastic limit. Philos Mag. 2016;96:1643-63. http://dx.doi.org/10.1080/14786435.2016.1177231.

16. Tong Y, Dmowski W, Bei H, Yokoyama Y, Egami T. Mechanical rejuvenation in bulk metallic glass induced by thermo-mechanical creep. Acta Mater. 2018;148:384-90. http://dx.doi.org/10.1016/j. actamat.2018.02.019.

17. Ross P, Küchemann S, Derlet PM, Yu H, Arnold W, Liaw P, et al. Linking macroscopic rejuvenation to nano-elastic fluctuations in a metallic glass. Acta Mater. 2017;138:111-8. http://dx.doi. org/10.1016/j.actamat.2017.07.043.

18. Priezjev NV. Cooling under applied stress rejuvenates amorphous alloys and enhances their ductility. Met. 2021;11. http://dx.doi. org/10.3390/met11010067.

19. Samavatian M, Gholamipour R, Amadeh AA, Mirdamadi S. Role of tensile elastostatic loading on atomic structure and mechanical properties of $\mathrm{Zr55Cu30Ni5A110} \mathrm{bulk} \mathrm{metallic} \mathrm{glass.}$ Mater Sci Eng A. 2019;753:218-23. http://dx.doi.org/10.1016/j. msea.2019.03.058.

20. Samavatian M, Gholamipour R, Amadeh AA, Mirdamadi S. Extra rejuvenation of Zr55Cu30A110Ni5 bulk metallic glass using elastostatic loading and cryothermal treatment interaction. J Non-Cryst Solids. 2019;506:39-45. http://dx.doi.org/10.1016/j. jnoncrysol.2018.12.007.

21. Samavatian M, Gholamipour R, Amadeh AA, Samavatian V. Inherent relation between atomic-level stresses and nanoscale heterogeneity in Zr-based bulk metallic glass under a rejuvenation process. Phys B Condens Matter. 2020;595:412390. http:// dx.doi.org/10.1016/j.physb.2020.412390.

22. Zhang S, Shi B, Wang J, Xu Y, Jin P. Rejuvenation of a naturally aged bulk metallic glass by elastostatic loading. Mater Sci Eng A. 2021;806:140843. http://dx.doi.org/10.1016/j.msea.2021.140843.

23. Priezjev NV. Accelerated rejuvenation in metallic glasses subjected to elastostatic compression along alternating directions. J NonCryst Solids. 2021;556:120562. http://dx.doi.org/10.1016/j. jnoncrysol.2020.120562.

24. Priezjev NV. Aging and rejuvenation during elastostatic loading of amorphous alloys: a molecular dynamics simulation study. Comput Mater Sci. 2019;168:125-30. http://dx.doi.org/10.1016/j. commatsci.2019.05.054

25. Zhang M, Wang YM, Li FX, Jiang SQ, Li MZ, Liu L. Mechanical relaxation-to-rejuvenation transition in a Zr-based bulk metallic glass. Sci Rep. 2017;7:625. http://dx.doi.org/10.1038/s41598017-00768-7.

26. Utiarahman A, Alkaim AF, Aljeboree AM, Venediktovna SZ, Takhirovna CO, Alexander M, et al. Role of elastostatic loading and cyclic cryogenic treatment on relaxation behavior of Cebased amorphous alloy. Mater Today Commun. 2021;26:101843. http://dx.doi.org/10.1016/j.mtcomm.2020.101843.

27. Chen SH, Li T, Chang WJ, Yang HD, Zhang JC, Tang HH, et al. On the formation of shear bands in a metallic glass under tailored complex stress fields. J Mater Sci Technol. 2020;53:112-7. http://dx.doi.org/10.1016/j.jmst.2020.02.082.

28. Zhao L, Chan KC, Chen SH, Feng SD, Han DX, Wang G. Tunable tensile ductility of metallic glasses with partially rejuvenated amorphous structures. Acta Mater. 2019;169:122-34. http:// dx.doi.org/10.1016/j.actamat.2019.03.007.

29. Wang P, Yang X. Atomistic investigation of aging and rejuvenation in $\mathrm{CuZr}$ metallic glass under cyclic loading. Comput Mater Sci. 2020;185:109965. http://dx.doi.org/10.1016/j. commatsci.2020.109965.

30. Louzguine-Luzgin DV, Zadorozhnyy MY, Ketov SV, Jiang J, Golovin IS, Aronin AS. Influence of cyclic loading on the structure and double-stage structure relaxation behavior of a Zr-Cu-Fe-Al metallic glass. Mater Sci Eng A. 2019;742:526-31. http://dx.doi.org/10.1016/j.msea.2018.11.031.

31. Lou Y, Liu X, Yang X, Ge Y, Zhao D, Wang H, et al. Fast rejuvenation in bulk metallic glass induced by ultrasonic vibration precompression. Intermetallics. 2020;118:106687. http://dx.doi.org/10.1016/j.intermet.2019.106687.

32. Li S, Huang P, Wang F. Rejuvenation saturation upon cyclic elastic loading in metallic glass. Comput Mater Sci. 2019;166:318-25. http://dx.doi.org/10.1016/j.commatsci.2019.05.007.

33. Samavatian M, Gholamipour R, Amadeh AA, Mirdamadi S Extra rejuvenation of $\mathrm{Zr} 55 \mathrm{Cu} 30 \mathrm{~A} 110 \mathrm{Ni} 5$ bulk metallic glass using elastostatic loading and cryothermal treatment interaction. J Non-Cryst Solids. 2019;506:39-45. http://dx.doi.org/10.1016/j. jnoncrysol.2018.12.007.

34. Ketov SV, Sun YH, Nachum S, Lu Z, Checchi A, Beraldin AR, et al. Rejuvenation of metallic glasses by non-affine thermal strain. Nature. 2015;524:200-3. http://dx.doi.org/10.1038/ nature 14674.

35. Sun K, Wang G, Wang YW, Chen HC, Yan L, Pauly S, et al. Structural rejuvenation and relaxation of a metallic glass induced by ion irradiation. Scr Mater. 2020;180:34-9. http:// dx.doi.org/10.1016/j.scriptamat.2020.01.023.

36. Kang SJ, Cao QP, Liu J, Tang Y, Wang XD, Zhang DX, et al. Intermediate structural state for maximizing the rejuvenation effect in metallic glass via thermo-cycling treatment. J Alloys Compd. 2019;795:493-500. http://dx.doi.org/10.1016/j. jallcom.2019.05.026.

37. Mendelev MI, Sordelet DJ, Kramer MJ. Using atomistic computer simulations to analyze $\mathrm{x}$-ray diffraction data from metallic glasses. J Appl Phys. 2007;102:43501.

38. Neelav AH, Pal S, Deng C. Atomistic investigation of the deformation mechanisms in nanocrystalline $\mathrm{Cu}$ with amorphous intergranular films. J Appl Phys. 2019;126:125101. http://dx.doi. org/10.1063/1.5119150.

39. Lo YC, Chou HS, Cheng YT, Huang JC, Morris JR, Liaw PK. Structural relaxation and self-repair behavior in nano-scaled $\mathrm{Zr}-\mathrm{Cu}$ metallic glass under cyclic loading: molecular dynamics simulations. Intermetallics. 2010;18:954-60. http://dx.doi. org/10.1016/j.intermet.2010.01.012.

40. Miyazaki N, Wakeda M, Wang Y-J, Ogata S. Prediction of pressure-promoted thermal rejuvenation in metallic glasses. Npj Comput Mater. 2016;2:16013. http://dx.doi.org/10.1038/ npjcompumats.2016.13.

41. Liu C, Guan P, Fan Y. Correlating defects density in metallic glasses with the distribution of inherent structures in potential 
energy landscape. Acta Mater. 2018;161:295-301. http://dx.doi. org/10.1016/j.actamat.2018.09.021.

42. Ding G, Li C, Zaccone A, Wang WH, Lei HC, Jiang F, et al. Ultrafast extreme rejuvenation of metallic glasses by shock compression. Sci Adv. 2019;5:eaaw6249. http://dx.doi. org/10.1126/sciadv.aaw6249.

43. Jiang S, Huang Y, Li M. Structural evolution in deformation-induced rejuvenation in metallic glasses: A cavity perspective. Chin Phys B. 2019;28:46103. http://dx.doi.org/10.1088/1674-1056/28/4/046103.

44. Cui X, Zhang XF, Li JJ, Zu FQ, Meng LZ, Lu J, et al. Centimetersized CuZrAl bulk metallic glass with good plasticity and chemical heterogeneity. Intermetallics. 2020;121:106773. http://dx.doi.org/10.1016/j.intermet.2020.106773.

45. Zhu F, Hirata A, Liu P, Song S, Tian Y, Han J, et al. Correlation between local structure order and spatial heterogeneity in a metallic glass. Phys Rev Lett. 2017;119:215501.

46. Sopu D, Foroughi A, Stoica M, Eckert J. Brittle-to-ductile transition in metallic glass nanowires. Nano Lett. 2016;16:4467-71.
47. Zhang Q, Li Q-K, Li M. Key factors affecting mechanical behavior of metallic glass nanowires. Sci Rep. 2017;7:1-8.

48. Jang D, Greer JR. Transition from a strong-yet-brittle to a stronger-and-ductile state by size reduction of metallic glasses. Nat Mater. 2010;9:215-9.

49. Shang B, Guan P, Barrat J-L. Role of thermal expansion heterogeneity in the cryogenic rejuvenation of metallic glasses. J Phys Mater. 2018;1:15001.

50. Sohrabi S, Ri MC, Jiang HY, Gu L, Wen P, Sun YH, et al. Prominent role of chemical heterogeneity on cryogenic rejuvenation and thermomechanical properties of $\mathrm{La}-\mathrm{Al}-\mathrm{Ni}$ metallic glass. Intermetallics. 2019;111:106497. http://dx.doi. org/10.1016/j.intermet.2019.106497.

51. Lang L, Tian Z, Xiao S, Deng H, Ao B, Chen P, et al. Molecular dynamics simulations of the structure evolutions of $\mathrm{Cu}-\mathrm{Zr}$ metallic glasses under irradiation. Nucl Instruments Methods Phys Res Sect B: Beam Interact with Mater Atoms. 2017;393:77-81. http://dx.doi.org/10.1016/j.nimb.2016.11.028. 